is a species of palm so unlike others with which it is associated as to have been accorded generic status, of which there is not even trace outside what is virtually a single island of one equatorial oceanic group, six hundred miles from any large land area -a palm moreover which, despite its enormous fruits, naturally colonizes steep hillsides, and which cannot establish itself on sandy sea shores, nor indeed even be dispersed in a viable state by ocean currents because of its specific gravity. What might not be learnt could we but see clearly the whole phyletic and geographical history of such a plant!

Ronald Good

\section{A FURTHER EXPERIMENT IN MARINE FISH CULTIVATION}

GEA fish for eating have still to be hunted, a $\$$ method of food-getting long ago abandoned on land by the most advanced peoples. Many have felt that it ought to be possible to grow sea-fish under controlled conditions to give a maximum return for minimum effort and expense; but it has not been oasy to see how to do it. During the Second World War, a courageous pioneer, the late Dr. Fabius Gross, initiated to this end an ambitious experiment in Loch Craiglin, Argyllshire, already reviewed in Nature ${ }^{1}$. The Loch proved in many ways unsuitable; but this set in high relief some of the factors which must prove of importance in any work of rearing sea fish.

An alternative loch was sought for a complementary study on the effect of fertilizers, and the adjacent Kyle Scotnish was chosen. The response of the flora and fauna to added nutrients has been assessed in terms of the neighbouring Sailean More, a very similar body of water which was left un. fertilized ${ }^{2}$.

Variations in abundance of phytoplankton can be completely explained in terms neither of nutrient distribution nor of grazing of plants by animals, nor indeed of both together. The authors discuss the effect upon reproduction of physiological changes in the diatoms themselves and of environmental chemical agents which had arisen from the metabolism of earlier inhabitants of the water. The nature of these chemical agents which affect growing organisms for good or ill is one of the great unsolved problems of marine ecology. Our ignorance provides a serious impediment to attempts such as this to understand and control the cultivation of sea fish.

Nevertheless, the experiments have clearly shown that the addition of nutrients in the form of ammonium sulphate and superphosphate to sea lochs causes an increase in plankton production and in the density of bottom-living animals, and an accelerated growthrate in plaice and flounders. Owing to the conditions for experimenting, no results could be obtained concerning the effect of fertilizers on round fish, nor could any relationship be established between the quantity of fertilizers added and the total yield of fish. For these reasons the actual economics of fertilizer application could not be assessed. These further experiments in Kyle Scotnish call, therefore, for no modification of our comment on the original Loch Craiglin reports (Nature, 161, see p. 631) to the effect that the experiments failed in their primary objective of demonstrating that maxine fish cultivation can be made to pay.

It is sad that Dr. Gross will now never again contribute to this important but difficult field of investigation.

G. A. Steven

L. H. N. COOPER

'Nature, 161, 631 (1948), and 162.378 (1948).

2 Proc. Roy. Soc. Edin., B, 64 (1950). A Fish Cultivation Experiment in an Arm of a Sea-loch. No. 1 , Introduction; by Dr. F. Gross 6d. No. 2, Observations on some Hydrographic Factors in Kyle Scotnish; by S. R. Nutman; 58 . No. 3, The Plankton of Kyle Scotnish ; by Dr. D. T. Gauld; 58. No. 4, The Bottom Fauna of Kyle Scotnish; by Prof. J.' E. G. Raymont; 78. 6d. No. 5 , Fish Growth in Kyle Scotnish; by Dr. F. Gross ; $48.6 d$.

\section{REGIONAL LIBRARY SYSTEMS IN GREAT BRITAIN}

$T$

HE Library Association has issued as No. 2 in its pamphlet series a survey of the regional library systems, their development through two decades and their possibilities for the future (pp. 36 ; London : Library Association, $1950 ; 3 s$. ; 2s. 6d. to members). This pamphlet, which is by Mr. P. H. Sewell, director of the South-Eastern Regional Library System, should be of particular interest at the present time, when the need for regional developments, in the technical and scientific field as well as generally, has been widely recognized. Mr. Sewell pays generous tribute to the help of the Carnegie United Kingdom Trust in initiating the regional system and to the leadership and administrative ability of Lieut.-Colonel J. M. Mitchell, Dr. Luxmoore Newcombe and many others whose enthusiastic co-operation has been the decisive factor in the success so far achieved. The concise picture given of the position in the various regions is only one valuable feature of the pamphlet. Equally important is the summary of the factors upon which the efficiency of a regional system depends.

First among these the author places the full-time direction of a competent librarian. All regions, he urges, should become self-sufficient in current nonfiction of the more serious type. Each region should also have access to the means of photographic reproduction both by photostat and by microphotography, and all large libraries should possess the necessary viewers. A co-ordinated system of contributing to, and filing periodicals within, each area is long overdue; and he suggests that, to supplement the service of the regional systems, the National Central Library, released from traffic in current non-fiction purchased in Great Britain, could buy on publication the most important works published in Europe and America, aided, if necessary, by the advice of appropriate national advisory bodies. The National Central Library should also become a copyright library on terms similar to the Universities of Oxford and Cambridge, or, alternatively, one of the existing copy. right libraries should participate in the scheme.

The greatest problem, however, is that of securing adequate funds for the regional systems. Regarding this, Mr. Sewell makes two recommendations : the substantial contribution of regional systems to the national inter-lending service and the real inadequacy of their finance should receive recognition both nationally and locally; and some action should be taken to ensure that these organizations, which arrange the great majority of inter-library loans in Great Britain, besides receiving the necessary financial support. also have a commensurate share in the planning of national inter-lending policy. 